\title{
Individual behavioural variability of an ecological generalist: activity patterns and local movements of Mallards Anas platyrhynchos in winter
}

\author{
Annette Sauter • Pius Korner • Wolfgang Fiedler • \\ Lukas Jenni
}

\begin{abstract}
Common and widespread species often show a large variability in behaviour and habitat use. Such variability at the species level may result from individuals themselves being very variable or, alternatively, variability may arise from differences between individuals. The aim of this study was to explore land use in general and betweensubject variability in the local movements and daily activity patterns of Mallards Anas platyrhynchos in central Switzerland during the winter. The Mallard is a common duck species and can be found on almost all types of water bodies. We equipped 24 ducks with VHF radio tags and searched for these ducks 1-3 times per day. We also used nine tags that automatically recorded their location every $30 \mathrm{~min}$ as well as acceleration in three dimensions every 2-5 min. These methods yielded information on the activity of the duck with a high temporal resolution both day and night. The 24 ducks were strongly linked to water,
\end{abstract}

Communicated by F. Bairlein.

A. Sauter · P. Korner $(\bowtie) \cdot$ L. Jenni

Schweizerische Vogelwarte Sempach, 6204 Sempach, Switzerland

e-mail: pius.korner@bluewin.ch

A. Sauter

e-mail: annettesauter@gmx.de

L. Jenni

e-mail: lukas.jenni@vogelwarte.ch

Present Address:

A. Sauter

Hoffmann-La Roche AG, 4070 Basel, Switzerland

W. Fiedler

Max-Planck-Institut für Ornithologie, Schlossallee 2,

78315 Radolfzell, Germany

e-mail: fiedler@orn.mpg.de and $97 \%$ of all localisations were within $50 \mathrm{~m}$ of a water body. An affinity to settlements was only observed in the vicinity of the main lake in the area, but not for those ducks on smaller water bodies or fields. Some individuals were very stationary, using only a small area during the study period; others made daily commuting flights between two sites about $8 \mathrm{~km}$ apart while still others moved around similar distances but in varying directions. Rain and increasing wind speed correlated with decreasing movement activity. However, the effect of these weather parameters, and especially that of temperature, varied between individuals. Activity was strongly influenced by the sun's movement, with general activity and flight activity being highest around sunrise and sunset. This daily pattern was similar for all individuals. Hence, while the activity pattern was similar for all individuals, the resulting degree of local movements and the response to changing weather parameters were very variable among individuals.

Keywords Mallard Anas platyrhynchos - Winter · Land use - Daily activity pattern

\section{Zusammenfassung}

Individuelle Variabilität im Verhalten eines ökologischen Generalisten: Aktivitätsmuster und lokale Ortswechsel bei der Stockente (Anas platyrhynchos) im Winter

Häufige und weit verbreitete Arten zeigen oft eine große Variabilität in Verhalten und Habitatnutzung. Diese Variabilität auf Artniveau kann sowohl durch ein vielfältiges Verhaltensrepertoir eines jeden Individuums entstehen, als auch durch große Unterschiede zwischen den Individuen. In dieser Studie untersuchten wir, wie Stockenten Anas 
platyrhynchos im Winter die vorhandenen Lebensraumtypen nutzten und wie sich das tägliche Aktivitätsmuster und die lokalen Ortswechsel zwischen den Individuen unterschieden. Die Stockente ist eine häufige Art, die fast alle verfügbaren Gewässertypen nutzt. Wir stellten den Aufenthaltsort von 24 mit VHF Radiosendern bestückten Individuen ein- bis dreimal täglich fest. Weitere neun Individuen wurden mit GPS-Sendern ausgerüstet. Die GPS-Ortung alle 30 Minuten sowie Beschleunigungsmessungen alle zwei bis fünf Minuten lieferten Informationen über das Verhalten dieser Enten mit großer zeitlicher Auflösung und über 24 Stunden am Tag. Die Stockenten waren stark an Gewässer gebunden. $97 \%$ aller Lokalisationen lagen innerhalb von $50 \mathrm{~m}$ um ein Gewässer. Eine Affinität zum Siedlungsraum wurde nur in der Nähe des größten Sees im Untersuchungsgebiet festgestellt, aber nicht bei den Enten, die kleinere Gewässer oder Felder nutzten. Einige Individuen waren sehr stationär und nutzten nur einen kleinen Raum während der ganzen Studie, andere wechselten täglich zwischen zwei acht Kilometer auseinander liegenden Aufenthaltsorten und nochmals andere Individuen legten ähnliche Distanzen zurück aber nicht in konstanten Richtungen. Zunehmender Regen und Wind korrelierten mit weniger weiten Ortswechseln. Dieser Wettereffekt, vor allem der Temperatureffekt, variierte allerdings deutlich zwischen den Individuen. Das Aktivitätsmuster wurde stark durch die Tageszeiten bestimmt: Um Sonnenauf- und -untergang war die Aktivität am höchsten und es fanden die meisten Ortsbewegungen durch Flug statt. Dieses tageszeitliche Muster war bei allen Individuen ähnlich. Das Ausmaß der Ortsveränderungen und die Reaktion auf Wettereinflüsse variierten aber zwischen den Individuen stark, was zu einer großen individuellen Variabilität der Raumnutzung führte.

\section{Introduction}

Species that use a large variety of habitats, such as the Mallard Anas platyrhynchos, are often termed a generalist. However, for many of these species, there is little information specifying whether each individual is a generalist or whether the observed variation at the species level results from between-individual variations in behaviour (Bolnick et al. 2003). In terms of land use and activity patterns, the search for an answer to this question has been hampered by the difficulty in following individuals with sufficient temporal resolution day and night. This problem has been overcome with the availability of small radio tags that use the global positioning system (GPS) and are equipped with built-in accelerometers that measure body motion.

The Mallard is among the most widespread duck species world-wide and is often associated with man. A characteristic of this species is its behavioural flexibility (Diefenbach et al. 1988; Tamisier 1978). Mallards breed and winter on almost all water bodies, both man-made and natural. Some individuals are shy and avoid contact with man, while others use urban areas and may be largely dependent on food provided by humans. For example, Kozulin (1995) described two sub-populations of Mallards wintering in the city of Minsk, Belarus. The "natural" sub-population usually rested during the day and foraged at night up to $30 \mathrm{~km}$ away, while the "urbanised" sub-population used anthropogenic food sources in the city and fed opportunistically day and night.

Mallards may forage on water or on land, especially on harvested fields (Baldassarre and Bolen 1984). They sometimes have distinct roosting (e.g. a lake) and feeding areas (fields), with a morning and an evening flight of typically up to $20 \mathrm{~km}$ (Jorde et al. 1983; Thomas 1982; Winner 1959). Night feeding is common in many duck species (Guillemain et al. 2002; McNeil et al. 1992; Owen 1991), and this behaviour in some species appears to be influenced by the amount of moonlight (McNeil et al. 1992), although no clear evidence of this has been presented for the Mallard. Weather parameters have also been demonstrated to affect the behaviour of the waterfowl (Paulus 1988). During cold times, foraging effort often increases, although at temperatures below freezing ducks may reduce foraging in order to remain in sheltered places (Jorde et al. 1983; Paulus 1988; Quinlan and Baldassarre 1984). Legagneux et al. (2009), on the other hand, found no strong influence of weather on the winter home-range size of Mallards. The timing of the foraging flights seem to be strongly influenced by daylight (Bossenmair and Marshall 1958; Paulus 1988; Tamisier 1976), with overcast skies possibly delaying flights, but feeding flights may still occur even during severe snow storms and dense fog (Bossenmair and Marshall 1958).

The Mallard has been defined as a "high-risk" species regarding the spread of the highly pathogenic avian influenza virus H5N1: it can carry this virus asymptotically and may come in contact with domestic birds when using habitats near human settlements (EFSA 2006; Keawcharoen et al. 2008). While the main reason for the large-scale spread of the highly pathogenic avian influenza virus H5N1 appears to be mainly associated with the poultry trade (Gauthier-Clerc et al. 2007), detailed knowledge of Mallard ecology is nevertheless relevant in order to determine which protective measures against the spread of pathogenic avian influenza viruses should be implemented and which should not.

The aim of this study is twofold. First, we present the general land use by wintering Mallards in our study area. Second, we explore the birds' movements (between days and within day) and the daily activity pattern, now focusing on variability between individuals. Within the framework 
of this second aim, we also look at the influence of weather parameters and moonlight on movement activity. In the "Discussion" of this article, we first discuss the general ecological aspects; conclusions relating to the avian influenza problem are summarised in the final paragraph.

Our methods combined the use of traditional manual telemetry (VHF-tags) with GPS-tags and acceleration measurements that yield high-resolution information about each bird's activity (Shepard et al. 2008). The automated localisation and acceleration measurements with the GPStag enabled a round-the-clock recording of the behaviour at the individual level and, therefore, yielded information on the degree of difference between individuals. Earlier studies on activity-budgets using traditional telemetry attained a much lower temporal resolution, while studies that visually measured the proportion of certain behaviours in flocks of ducks contained no information on individual differences and were mostly restricted to daytime observations.

\section{Methods}

Study area

The Mallards studied were found in central Switzerland at Lake Sempach and in an area of about $10 \mathrm{~km}$ to the west and north of this lake (Fig. 1; coordinates of the centre: $47^{\circ} 10^{\prime} \mathrm{N}, 8^{\circ} 4^{\prime} \mathrm{E}$; study area 19,260 ha). Lake Sempach measures $7.5 \times 2.3 \mathrm{~km}(1,420 \mathrm{ha})$. Three smaller lakes $(3.3,24$ and $200 \mathrm{ha})$ and several ponds are within the study area as well as a dense network of small to medium-sized streams. The largest municipality, Sursee, with adjacent villages at the northern end of Lake Sempach, has about 15,000 inhabitants. Several other villages and many small settlements and farms are scattered over the entire area. Built-up areas account for $4 \%$ of the study area, lakes for $2 \%$ and forests for 5.5\%; most of the remaining area $(88.5 \%)$ is used for livestock farming (mainly grassland; in flat areas also for cultivating maize and other crops). Marsh areas (mostly around lakes) cover about $0.2 \%$ of the study area. The lower altitudes of the study area are at approximately $500-600 \mathrm{~m}$ a.s.1., with the hills rising to $700 \mathrm{~m}$ a.s.l; the study area is bordered by hills which rise to $850 \mathrm{~m}$ a.s.l. in the east.

\section{Catching and telemetry}

Mallards were caught at four sites within the study area (Fig. 1). At the "obe" site, we used a large wire mesh trap (length $12 \mathrm{~m}$, height $1.5 \mathrm{~m}$ ) that has been in place since 1950 for waterbird ringing (see Hofer et al. 2010 for details); at the other three sites, we built one trap for each

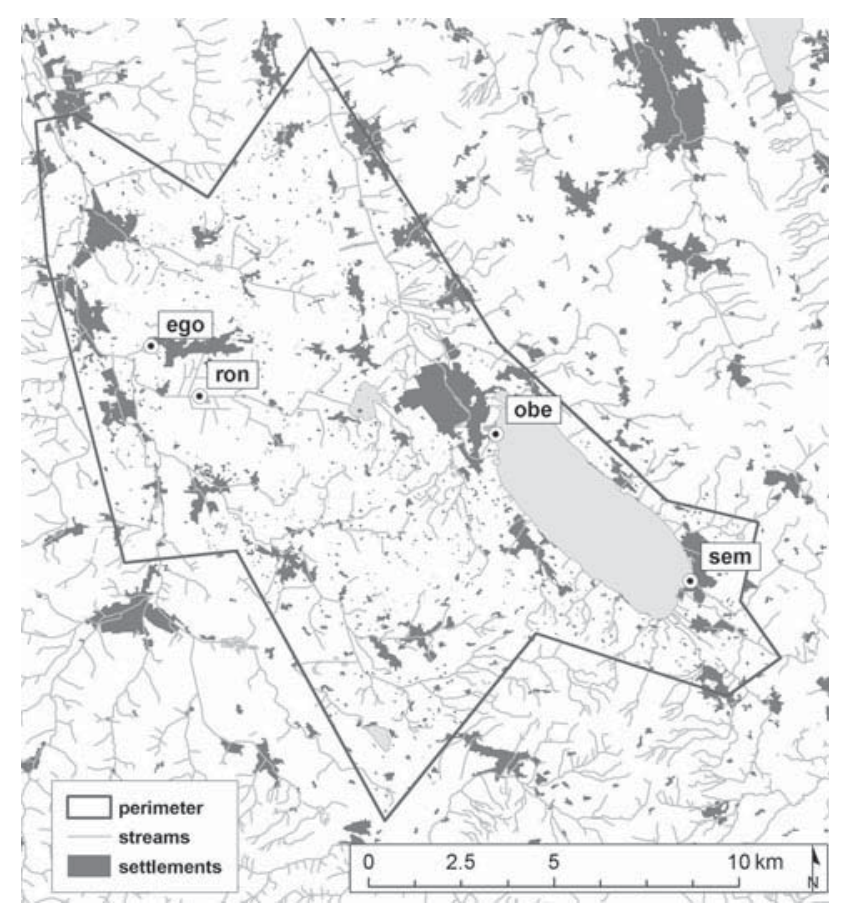

Fig. 1 Study area with Lake Sempach to the south-east. Very small "settlements" are mainly farms (only shown within the study perimeter). ego, ron, obe, sem Sampling locations. Base map was provided by the Federal Office of Topography (swisstopo; contract nr. DV002232.1)

site for this study. The traps at "ron" and "ego", 8 and $9 \mathrm{~km}$ west of Lake Sempach, respectively, were made of wood and wire mesh $(1 \times 1.5 \times 0.5 \mathrm{~m})$ with styrofoam attached so that the traps were "swimming" and the floor flooded with $10 \mathrm{~cm}$ of water, which allowed ducks to swim freely into the traps. One of these two traps was placed at the water's edge of a canal ( $6 \mathrm{~m}$ wide) and the other $2 \mathrm{~m}$ into a small lake (3.3 ha); both were fixed to poles. The trap "sem" at the southern end of Lake Sempach was a walk-in trap with a V-shaped funnel made of metal wiremesh elements $(1 \times 4 \times 1 \mathrm{~m})$. It was placed on the beach $1 \mathrm{~m}$ from the lake shore in a public swimming area that was not used and fenced off during the winter. Many ducks in this area were likely accustomed to being fed by the public (the site is next to the small town of Sempach). The other three sites were semi-natural, where the ducks had comparatively little direct human contact and were not fed by the public. The three traps constructed at these sites for this study were first left open and baited with maize and oat grains daily until Mallards were observed visiting the trap, which took about 3 weeks. Thereafter, we continued to provide food and started capturing. Traps were checked at 4-h intervals or less. The trap "obe" was in permanent use, and waterbirds were attracted into the trap using maize and fish offal as bait. 
Captured Mallards were fitted with either of two types of tags. The first was a TW3 radio-tag (Biotrack Ltd, Wareham, UK; hereafter called VHF-tags) with a harness of natural rubber (diameter $2 \mathrm{~mm}$ ); total weight including harness was $6 \mathrm{~g}$. The second was a GPS data-logger (e-obs Digital Telemetry, Grünwald, Germany; hereafter called GPS-tags) with a harness of 25-inch natural tubular Teflon (Bally Ribbon Mills, Bally, PA); the total weight was $44 \mathrm{~g}$. We did not equip ducks with the GPS-tag if they weighed $<1 \mathrm{~kg}$ at capture (i.e. tags were $<4.5 \%$ of body mass). The harness was designed as described in Roshier et al. (2006). A 3-cm-long piece of shrinkable tubing with a diameter of $3 \mathrm{~mm}$ (Klebeschrumpfschlauch; product nr. 121-0512, Farnell, Zurich, Switzerland) was used to form the T-loop on the breast.

The GPS-loggers were programmed to record their position at 30 -min intervals throughout the day. If a position fix failed, the next position fix was attempted $30 \mathrm{~min}$ later. The tags were also set to record the acceleration every 2, 3 or $5 \mathrm{~min}$ (depending on the tag). For each such measurement, the acceleration of the three axes $X, Y, Z$ was recorded during a $17-\mathrm{s}$ interval and at $10.5 \mathrm{~Hz}$ per axis (7.3 s and $18.7 \mathrm{~Hz}$ for one tag). Between 0900 and 1200 hours the GPS-tags emitted a ping signal and could be located using a Yagi-antenna and radio receiver (Yaesu VR-500; Vertex Standard, Cyprus, CA) to download the data from the tag weekly.

We attempted to locate each individual with a VHF-tag one to three times a day. We did 66 night shifts (22000600, $n=606$ localisations), 109 morning shifts (0600$1400, n=1,222)$ and 101 afternoon shifts (1400-2200, $n=1,087$ ). We searched the study area (Fig. 1) and areas about $1 \mathrm{~km}$ beyond using fixed and mobile receiver antennas. Individuals which could not be located were searched for at least 2 further days and also in neighbouring valleys. Individuals with GPS-tags were located every 1-2 days. For the VHF-tags we noted the estimated precision of the localisation in the field and excluded those with $>100 \mathrm{~m}$ from the final analysis. We estimate that the mean precision was around $10 \mathrm{~m}$ for VHF-localisations and clearly less than $10 \mathrm{~m}$ for GPS localisations, although single GPS localisations may be off by several dozens of meters according to the operating manual.

A total of 29 and nine Mallards were fitted with a VHFand GPS-tag, respectively. Five VHF-individuals were excluded because they produced less than ten localisations. Individuals could be followed for 9-125 days during the winter of 2008/2009 (Fig. 2).

Based on the VHF data, it was impossible to determine whether some individuals temporarily left the study area. None of the GPS-tagged individuals left the study area during the time we recorded its positions, which suggests that non-detection of VHF-tagged individuals was not due

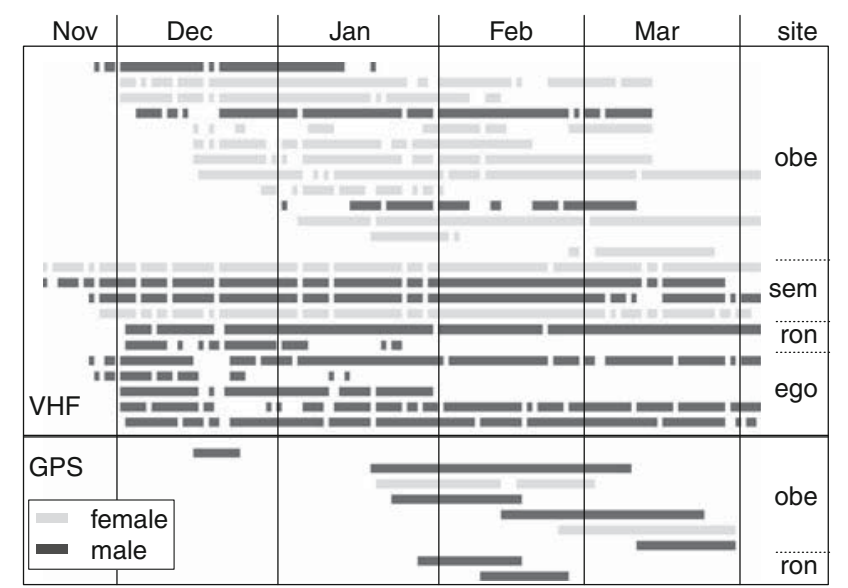

Fig. 2 Days with at least one localisation for each of 24 individual Mallards equipped with VHF-tags (above) and nine individuals equipped with GPS-tags (below). Each line is one individual and days with localisations are marked black for males and grey for females. Individuals are grouped according to the site of ringing which is indicated to the right (cf. Fig. 1). The total number of localisations was 27-210 (mean 120) for VHF-tagged Mallards and 343-2,233 (mean 1,218) for GPS-tagged Mallards. The observation period spanned 17 November 2008 to 3 April 2009

to the birds being away, but to the fact that the signal could not be received because the bird was under dense vegetation, in deep ditches, etc. Technical failure, loss of the tag or departure from the study area could all be responsible for the loss of recordings before the end of the study period in early April 2009. One individual was shot during the study period, another most likely as well.

Geographic data, daytime data and weather data

We used the digital landscape model of Switzerland (VECTOR25 (c) swisstopo), which includes all permanent streams at least $100 \mathrm{~m}$ in length, i.e. essentially all water bodies suitable for Mallards. Primary surfaces relevant to our study were settlements, woods, lakes, marsh areas and "remaining area", which is, in our study area, mainly farmland. Because, in the digital landscape model, "remaining area" also includes farms and other isolated buildings, we manually added these buildings to the settlement layer using the orthophotos SWISSIMAGE (c) swisstopo; years 2004-2007) on which all buildings are easily visible. Distances of duck localisations to settlements and water bodies were calculated in a Geographic Information System (GIS).

Twilight hours and sun and moon rise and set times were obtained from the Astronomical Applications Department of the U.S. Naval Observatory (http://aa.usno.navy.mil/data/ docs/RS_OneYear.php) for the coordinates of the northern end of Lake Sempach $\left(8^{\circ} 6^{\prime} \mathrm{E}, 47^{\circ} 10^{\prime} \mathrm{N}\right)$. We added $10 \mathrm{~min}$ 
to the sun and moon rise times and subtracted 10 min from the set times to account for the slightly elevated horizon (personal observation). Standard twilight phases are the astronomical twilight (before/after which the sky is fully dark except for moon and stars), nautical twilight (some stars visible) and civil twilight (enough light to read). Mean (and range of) sunrise and sunset times in our study area and during our study period were 0750 (0617-0829) hours and 1725 (1633-1855) hours, respectively. The duration of each twilight phase was always $35 \pm 5 \mathrm{~min}$. We used a moonlight index fitted with a sinus curve between 0 (at new moon) and 1 (at full moon); when the moon was below the horizon, the index was set to 0 .

Weather parameters were available from meteorological stations at Sempach (daily total precipitation) and Lucerne (about $10 \mathrm{~km}$ to the southeast of Sempach; mean day temperature and wind speed).

\section{Accelerometer data}

A total of 123,574 accelerometer bouts of $17 \mathrm{~s}$ ( or $7.3 \mathrm{~s}$ in one bird) were recorded from the nine GPS-tagged individuals. The accelerometers were not calibrated and, therefore, the exact physical value of the acceleration could not be computed. However, the pattern of the changes in acceleration allowed us (1) to categorise the level of activity (inactive vs. active) and (2) identify flying individuals.

For both aims we performed a fast Fourier transformation of the raw acceleration data of each 17-s (7.3-s) bout to calculate, for each axis, the energy spectral density (i.e. the energy per frequency). Accelerograms with a mean maximal energy per axis (mme) of $<3,000$ always showed nearly straight lines, i.e. hardly any change in the acceleration and, thus, corresponded to inactive individuals. Small deflections yielded a mme of $>5,000$, while very strong and regular movements, such as flying, produced values $>100,000$. A problem was that ducks resting on agitated water produced a mme of $>3,000$ without actually being active. To address this problem, we plotted the mme against the correlation of the energies of the $Y$ - and $Z$-axis. This correlation (anterior-posterior with up-down) apparently results from ducks resting on water with waves: we observed a cloud of points where the $Y Z$-correlation was larger than about 0.42 and where the correlation was higher with increasing mme (but with mme $<10,000$, i.e. much lower than flying). In accordance with our hypothesis that such ducks were resting on (agitated) water, the nearest GPS positions of these cases (only for cases with a GPS position $<3$ min apart) were almost all on a lake. Therefore, bouts with a $Y Z$-correlation $>0.42$ and small mme $(<3,000$ at $Y Z$-correlation 0.42 to $<10,000$ at
$Y Z$-correlation 1) were also categorised as inactive (contributing $1.2 \%$ of all cases finally identified as inactive). All other bouts were categorised as active.

Flight produced a very clear pattern and, correspondingly, was easy to recognise: high energy values (mme $>100,000)$ and very regular, strong oscillations on all axes. Moreover, birds identified as flying from the acceleration data also had their speed measured by the GPS-tag (which was performed during each GPS localisation) and did show a speed corresponding to the flight speed of a Mallard. However, since acceleration was measured at a much higher cadence than speed, we used acceleration to identify flying. In total, of the 123,574 recorded acceleration bouts, 76,718 were classified as inactive and the remaining 46,856 as active, with the latter including 916 bouts in flight.

All data analysis was done using R2.9.2 for PC ( $\mathrm{R}$ Development Core Team 2009) and ArcGIS 9. Mixed models were calculated using the function lmer from the package lme4 in R (Bates and Mächler 2010).

\section{Results}

Land use

In order to prevent a bias due to an unequal number of localisations per individual (especially between VHF- and GPS-tagged individuals), we randomly selected one localisation per individual and per half day (half day$\mathrm{s}=0000-0600$ hours $+>1800-2400$ hours,

and $>0600-1800$ hours) for subsequent analyses of land use patterns.

The observed Mallards were strongly associated with water (Fig. 3). Of the 2,694 localisations, 93\% were on or within $20 \mathrm{~m}$ of a water body, and $97 \%$ were within $50 \mathrm{~m}$; maximal distance from water was $320 \mathrm{~m}$. Lake shores and streams were used regularly. Most of the water bodies used were open or lined with scattered trees and bushes, but small streams with very dense vegetation (bushes) were also sometimes used. However, water bodies inside of woods were not used at all. The pattern seen in Fig. 3 is very similar to that found using only night, dawn, daytime or dusk localisations.

Mallards $>20 \mathrm{~m}$ away from a lake or a stream (445 localisations) used marsh areas more often than expected by chance $(6.5 \%$ of these localisations were in marsh areas which made up only $0.2 \%$ of the area $>20 \mathrm{~m}$ from water bodies). The Mallards clearly avoided woods [0.7 vs. $13 \%$ (random)] and used cultivated land and settlements approximately in proportion to their occurrence [79 vs. $73 \%$ (random) and 14 vs. $13 \%$ (random), respectively]. 


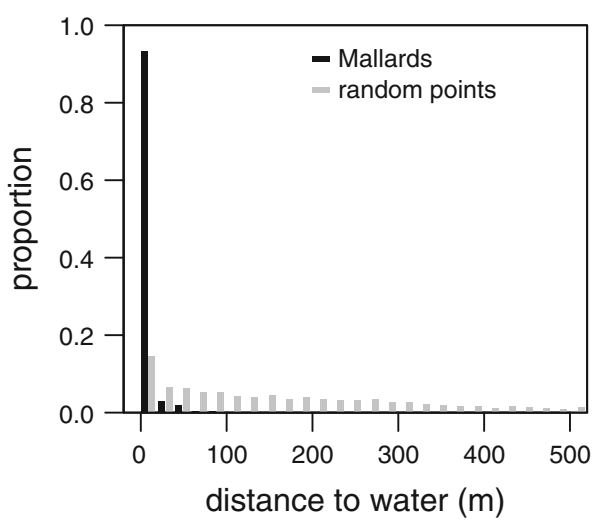

Fig. 3 Distance to water of tagged Mallards (black, $n=2,694$ selected localisations, see text) compared to random points within the study area (grey, 5,000 points, shown only up to $520 \mathrm{~m}$; the maximum distance was $1,140 \mathrm{~m}$ )

The question of whether Mallards seek the vicinity of settlements (which included built-up areas as well as single buildings, as described in the "Methods") is complicated by the fact that settlements do not occur independently of the hydrography because there is a clustering of settlements at the shores of Lake Sempach. For this reason we separately looked at the area in the vicinity of Lake Sempach (up to $200 \mathrm{~m}$ from the shore) and areas $>200 \mathrm{~m}$ away. In the vicinity of Lake Sempach, Mallards showed some affinity to settlements: $40 \%$ of the Mallard localisations were within $20 \mathrm{~m}$ of settlements, compared to only $18 \%$ of the corresponding random points (only random points within $200 \mathrm{~m}$ of Lake Sempach and within $50 \mathrm{~m}$ of a water body, i.e. from the area Mallards were using regularly). This overrepresentation of localisations close to or in settlements was mainly due to Mallards using the shore at the town of Sempach. Also, Mallards concentrated near the permanent trap at the northern end of the lake where there are single buildings, hence increasing the percentage of localisations near settlements. On the other hand, for ducks some distance from Lake Sempach (>200 m), the distance to settlements was similar as that expected by chance $(13 \%$ of Mallard localisations were $<20 \mathrm{~m}$ away from a house or settlement vs. $20 \%$ of the corresponding random points; for the distance up to $100 \mathrm{~m}$ from the settlement, the percentage values were 38 vs. $49 \%$ ). In particular, Mallards neither sought nor strongly avoided the vicinity of farms, except that they were never observed entering the actual farm premises.

\section{Movements between days}

To obtain a measure of the degree of movements between days, we used a gliding 3-day interval. For each such interval and for each individual, we selected the largest distance between any two localisations as a measure of the range the individual was using at that time of the season. An advantage of this parameter is that it allows the data on birds with VHF- and GPS-tags to be compared despite the very different number of localisations. We observed large differences between individuals, with some using only a very restricted area while others made major movements (Fig. 4 and Appendix Fig. 7). Mallards caught near Sempach used a very small home range of $<100$ ha (minimum convex polygon) over a time period of 40 to $>100$ days; the smallest home range was 16 ha-for an individual over a period of 118 days ("sem01"). Some of the individuals trapped at the other end of Lake Sempach, the more natural area of Oberkirch ("obe" in Fig. 1), also used an area of only 80-300 ha, while others from the same place used 2,000-5,000 ha, which was comparable to the individuals caught $8-10 \mathrm{~km}$ away from Lake Sempach (maximum was 6,367 ha over 109 days).

All 33 individuals were recorded visiting Lake Sempach at least a few times; most individuals used the lake regularly (small black dots in Figs. 4 and 7). Even the nine birds caught at the two sites 8 and $9.5 \mathrm{~km}$ away from Lake Sempach ("ego" and "ron" in Fig. 1) more or less regularly came to this main water body in the area. Birds caught at the southern end of Lake Sempach (names starting with "sem" in Fig. 4) were very stationary; they moved at most $1.6 \mathrm{~km}$ away from the lake. These birds were accustomed to human food supplementation (personal observation). Among the birds ringed at the northern end of Lake Sempach ("obe") some were regularly visiting sites up to $8 \mathrm{~km}$ away from the lake.

Some of the tagged individuals showed alternating periods of large and reduced movements (e.g. "ego01", "ego05", "ron01"). We did not recognise a systematic change in the movement patterns across our study period or a clear gender difference (Fig. 4, Appendix Fig. 7). Although the GPS data are based on one localisation every 30 min and VHF-data on one to three localisations per day, the variability of the estimated range per individual was within the same limits for both types of tags.

Within-day movements and influence of weather

For the analysis of within-day movements we could only use the data on the nine GPS-tagged individuals with localisations every $30 \mathrm{~min}$. From the field work it was evident that movements often occurred at dawn and dusk. Therefore, we analysed movements occurring in nine periods of the day: night 1 ( $0 \mathrm{~h}$-start of astronomical twilight), astronomical, nautical and civil twilight in the 

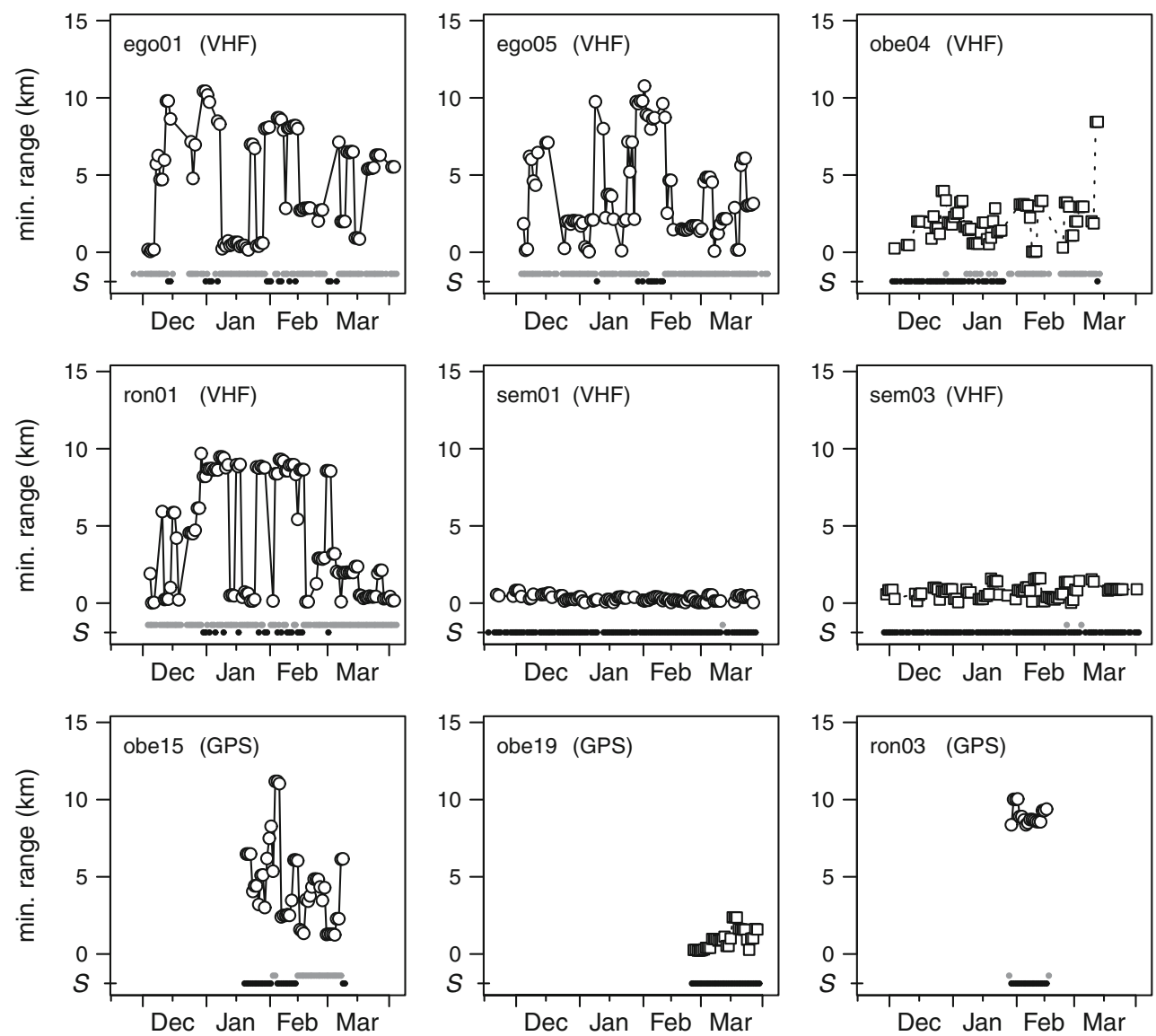

Fig. 4 Minimum range spanning 3-day periods (gliding 3-day window). Each plot corresponds to one individual; its name also identifies the site of ringing (see Fig. 1), and the type of tag (VHF, GPS) is indicated. All localisations per 3-day period and per individual were considered, and the largest distance between any two of them is plotted over the middle day of the 3-day period.

morning, day (from sunrise to sunset), civil, nautical and astronomical twilight in the evening ( $35 \pm 5 \mathrm{~min}$ for all twilight periods) and night2 (end of astronomical twilight to midnight). When the 30-min measurement interval spanned across 2-day periods, it was assigned to that of the central time point of the interval. We modelled the average distance per 30-min interval depending on dayperiod and weather parameters (fixed factors and covariates, respectively) with the individual and the date as random factors. The interaction day-period $x$ individual was also included in the model. Two of the nine GPStagged individuals were ringed $8 \mathrm{~km}$ to the west of Lake Sempach ("ron" in Fig. 1) and these individuals carried out daily flights to Lake Sempach, while the other seven individuals ("obe") only used the lake and its surroundings. For this reason we also included the factor "site of ringing" with the levels "ron" and "obe" in the model
Circles, solid lines Males, squares, dashed lines Females. At the bottom of each plot, small black dots identify days during which the individual was at least once at Lake Sempach ( $S$ on the y-axis), grey dots are days with all localisations $>100 \mathrm{~m}$ away from Lake Sempach. Typical cases are shown here; all others in the Appendix (Fig. 8)

(Table 1), as well as its interaction with the factor of interest, i.e. day-period.

Average movement distance strongly depended on the day-period, with peak activity occurring during the nautical morning twilight and civil and nautical evening twilight (Fig. 5). The two individuals ringed at "ron" (light-grey circles in Fig. 5) flew to Lake Sempach almost every morning and returned in the evening. Correspondingly, the interaction day-period $x$ site of ringing contributed strongly to the model (Table 1). In addition, the interaction day-period $\times$ individual still remained important, indicating that also within the site of ringing the individuals varied in their movement behaviour.

The largest displacements during a 30-min interval were almost $10 \mathrm{~km}$, and these were mainly observed during civil and nautical twilight, but also during the day (mostly before noon). Displacements of up to $2 \mathrm{~km}$ within $30 \mathrm{~min}$ 
Table 1 Linear mixed model for movement distance per 30-min interval (log-value) of Mallards (GPS-tags only)

\begin{tabular}{lllll}
\hline Deleted term & $K$ & AIC & LR & $P$ \\
\hline (None) & 33 & 39448 & - & - \\
Day-period $\times$ ind & 32 & 39475 & 18.3 & $<0.001$ \\
Rain $\times$ ind & 30 & 39451 & 8.5 & 0.001 \\
Temperature $\times$ ind & 30 & 39460 & 16.9 & $<0.001$ \\
Wind $\times$ ind & 30 & 39452 & 10.6 & 0.001 \\
Day-period $\times$ site of ringing & 25 & 39491 & 71.7 & $<0.001$ \\
\hline
\end{tabular}

$\mathrm{K}$, Number of estimated parameters; AIC, Akaike information criterion; LR, likelihood ratio, $P, P$ value obtained by parametric bootstrap (Faraway 2006)

Explanatory variables are day-period (see text), weather parameters and site of ringing, as well as the random variables individual ("ind") and date. Values for single term deletion are indicated. The full model (no deleted terms) was: $\log ($ dist $) \sim$ day-period + rain + temperature + wind + site of ringing + ind + date + day-period $\times$ ind + rain $\times$ ind + temperature $\times$ ind + wind $\times$ ind + day-period $\times$ site of ringing. If a deleted term has a $P$ value $<0.05$, this term significantly contributes to explain variation in movement distance

Weather parameters were standardised. Temperature and wind speed are mean daily values, rain is the total precipitation per day, site of ringing is either at Lake Sempach ("obe" in Fig. 1) or 8 km away ("ron")

were regularly observed day and night. The largest distance covered on one entire day (i.e. the sum of all displacements measured over $24 \mathrm{~h}$ ) was $23 \mathrm{~km}$.

Weather influenced the distance travelled (interactions of rain, temperature and wind speed with individual are significant; Table 1). In order to quantify the effect of the interaction, i.e. the variation among individuals, we looked at the estimated slope for each individual and for each weather parameter (function "ranef" in R). Model estimates suggest a general decrease in travel distance with precipitation (except for two individuals which showed no correlation with precipitation): across the observed precipitation values (daily totals ranged from 0 to $15 \mathrm{~mm}$ ), movement distances decreased by about 20-40\%, depending on the individual. Similarly, distances generally decreased with wind speed (mean daily wind speed ranged from 0.6 to $5.2 \mathrm{~m} / \mathrm{s}$; decrease of movement distances across this range was $10-50 \%$ depending on the individual), although for one individual the model estimated an increase of $30 \%$. Temperature had a more variable effect on individual movement, with distances decreasing by as much as $40 \%$ or increasing by up to $100 \%$ across the range of mean day temperature $\left(-4\right.$ to $\left.9.5^{\circ} \mathrm{C}\right)$ depending on the individual.

We separately analysed the distances covered during the night (i.e. after evening and before morning astronomical twilight, i.e. without any sunlight), focusing on the effect of moonlight. To this end, we built a model analogous to the one described in Table 1 but replaced day-period with the moonlight index (see "Methods"). Because the correlation between moonlight index and distance was non-linear (visual inspection of the data), we grouped the moonlight

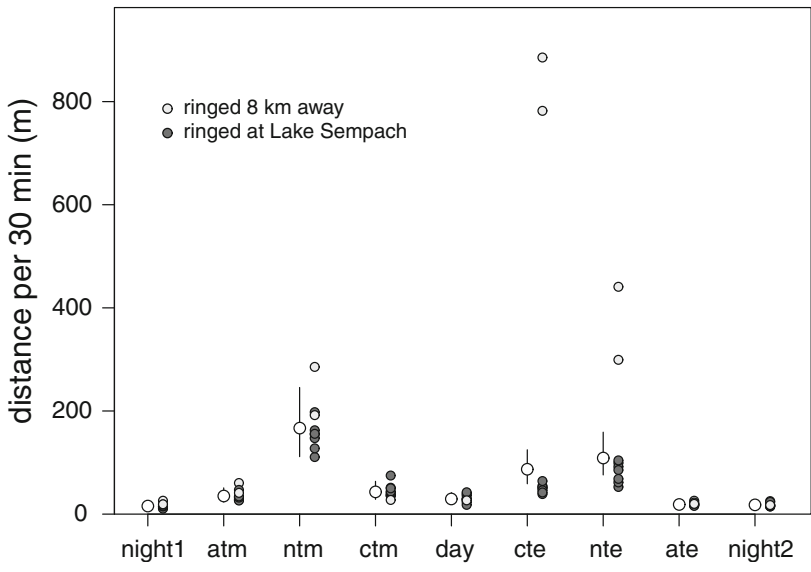

Fig. 5 Distance (geometric mean, predicted from the model in Table 1) travelled per $30 \mathrm{~min}$ and per period of the day by nine Mallards fitted with a GPS-tag. The periods of the day ( $x$-axis) are: night1 $0 \mathrm{~h}-$ start of astronomical twilight, atm astronomical twilight morning, ntm nautical twilight morning, ctm civil twilight morning, day sunrise to sunset, cte civil twilight evening, nte nautical twilight evening, ate astronomical twilight evening, night 2 night until 2400 hours. White circles with 95\% credible intervals (Gelman and Hill 2007) indicate the population estimate given as the mean value for rain, wind speed and temperature, including their interactions with individual as well as the interaction individual $\times$ day-period, but ignoring site of ringing. Estimates for all nine individuals are also given for each period, with the model now also including site of ringing and its interaction with day-period. Black dots Seven individuals ringed at Lake Sempach ("obe" in Fig. 1), grey dots two individuals ringed at "ron"

index into six discrete levels and used it as a factor: no moon, $<0.2,<0.4,<0.6,<0.8,0.8-1)$. In this model, the interactions between individual and each of the three 
weather parameters were significant (all parametric bootstrap $P$ values $<0.001$ ), as for the above model with day-period (Table 1). The interaction moonlight $\times$ individual was also significant $(P<0.001)$, but a look at the interaction plot (now with individual as a fixed factor to prevent shrinkage of the estimates) revealed no distinct pattern. In particular, distance covered neither increased at or near the period of the full moon nor decreased with little or no moonlight. In fact, large movements were observed even in the absence of any sunlight or moonlight; for example, a flight of $5.8 \mathrm{~km}$ along the shore of Lake Sempach $1.5 \mathrm{~h}$ after astronomical twilight and no moon; a flight from a small river $3.1 \mathrm{~km}$ away from Lake Sempach to Lake Sempach $2 \mathrm{~h}$ after astronomical twilight and no moon; a flight of $2.3 \mathrm{~km} 2.5 \mathrm{~h}$ after astronomical twilight and no moon - this bird started from a stream, followed it upstream and landed again in the stream.

\section{Activity}

Duck activity was measured by the accelerometer in the GPS-tags (9 individuals) every $2-5 \mathrm{~min}$. Activity was highest around sunrise and just after sunset, with about $50-60 \%$ of all measurement bouts during these periods indicating at least some activity (Fig. 6, left). Between these two peaks, during daylight hours, activity was somewhat reduced. Minimal activity was observed from about $2 \mathrm{~h}$ after sunset to $2 \mathrm{~h}$ before sunrise (i.e. during astronomical twilight and night), when only around $30 \%$ of the bouts indicated activity. This activity pattern over the day was similar in all individuals (see Appendix Fig. 8). Therefore, the variability among individuals seen in the movement distances was not present to the same degree in the pattern of activity over the day.

Two very clear peaks were observed for flying, one just before sunrise and one just after sunset (Fig. 6). During the rest of the day flying was observed much less, albeit somewhat more often during the daylight hours than during the night.

\section{Discussion}

The results of this study demonstrate that the behaviour of Mallards during the winter and in an area with a central lake and many small water bodies in the surroundings was strongly linked to water, with all tagged Mallards visiting the central lake at least occasionally. The ducks did not show a preference for staying in or close to settlements, except to some degree at the lake. The daily activity pattern was similar for all individuals, but the distances covered daily and between days varied largely among individuals.

In order to reveal differences in behaviour between individuals, we used VHF-tags that provided one to three positions of the bird per day and GPS-tags that recorded the location of the bird almost continuously as well as its body movements in three dimensions through the attached accelerometers. VHF-tags are cheaper and, therefore, can be put on more individuals than the more expensive GPStags. On the other hand, the GPS-tags with accelerometers provide a huge amount of data, i.e. localisations as well as behavioural data. An advantage of the GPS-tags is that they provide data on individual activity without the need to actually see the bird (i.e. even when the bird is moving away or at dark). In contrast, classical field studies on timeactivity budgets often provide data on the proportion of the population involved in a specific behaviour at a specific time, but they cannot follow individuals for prolonged periods.

The nine Mallards equipped with a GPS-tag never left the study area during the study period. We also have no evidence that any of the 24 individuals with a VHF-tag temporarily left the area, i.e.. none was found in a
Fig. 6 Activity of Mallards throughout the day. For each hour relative to sunrise (left dashed line) and sunset (right dashed line) the graphs indicate the proportion (average of the mean proportions per individual to balance unequal sample sizes) of active versus inactive ducks (left) and of flying ducks (right)
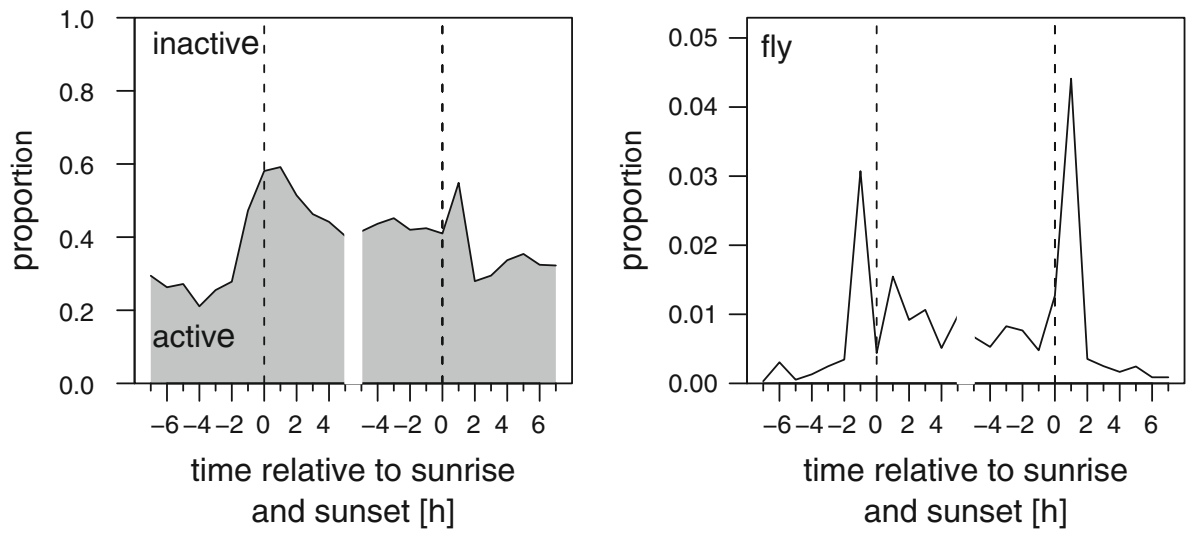
neighbouring valley, although we were not able to record a duck that may have ventured even farther. Therefore, the range of wintering Mallards - at least for the time we were able to record the individual-did not exceed the study area of about $200 \mathrm{~km}^{2}$, even when mean day temperatures fell to around $-4{ }^{\circ} \mathrm{C}$ from the end of December to midJanuary. However, because we could not distinguish between mortality, tag-failure and permanent emigration, we cannot exclude the possibility that some of the individuals we were unable to record up to the end of the study period (see Fig. 2) may have moved away over larger distances, as has been reported for Mallards in response to adverse weather (Diefenbach et al. 1988; Robb 2002; Sauter et al. 2010).

Many dabbling duck species, including the Mallard, readily go onto land and away from water to forage. However, the Mallards in our study were always within $320 \mathrm{~m}$ of water, with the great majority of localisations being within $20 \mathrm{~m}$. Mallards overwintering in Nebraska were also observed to spend at least $94 \%$ of their time at a water body (Jorde et al. 1984). But unlike all other wildfowl species in our area, the Mallards penetrated much deeper into the hinterland, away from larger water bodies. In an earlier study, Mallards tracked at Lake Constance were also found to venture several kilometres into the hinterland in winter (W. Fiedler in Brunhart et al. 2010).

The movements of the Mallards we studied varied strongly among individuals. Some used a very small area of $<100$ ha. These were mainly the ducks caught near the small town Sempach and they appeared to be typical "urbanised" ducks as described by Kozulin (1995). Individuals trapped in the more natural area of Oberkirch ("obe" in Fig. 1) either used a restricted area of only 80-300 ha or a larger area of 2,000-5,000 ha, which was comparable to the individuals caught 8-10 km away from Lake Sempach. These latter values are similar to those observed in Nebraska in winter (Jorde et al. 1984). The variability in the size of home range of birds at "obe" confirms the high inter-individual variation of Mallards occurring at the same spot. However, there was also a large intra-individual variation in the movements of some individuals, i.e. they apparently used a large home range on a number of consecutive days and a small home range on subsequent days. However, we could not detect a general change in home range size throughout the season.

We did not observe a general day-roost-night-foraging pattern as has been described, for example, for the Common Teal Anas crecca (Tamisier 1976) and, occasionally, for the Mallard (Kozulin 1995), although we did see a certain pattern depending on the catching site. Individuals from "ego" (Figs. 1 and 4) moved around a lot, with little regularity. Mallards from "ron", less than $2 \mathrm{~km}$ away from "ego", moved to Lake Sempach to spend the day there and returned to "ron" in the evening, i.e. they showed a commuting behaviour. Mallards caught at "obe" were not homogeneous in terms of their movements, with some remaining at the lake all of the time and others venturing into the hinterland to small rivers, ponds or fields at night. Finally, birds from "sem" were typical "urbanised" Mallards and moved around very little. The small lake of the catching site "ego" froze completely during the cold spell in January. However, ducks from "ego" showed large and variable movements even before this time, suggesting that their high mobility was not solely induced by the freezing of their water body.

Individuals that did not stay at Lake Sempach for most of the time nevertheless visited this largest water body in the area at least occasionally. This could be a coincidence because these individuals generally moved around a lot in the area. Alternatively, the individuals may have visited the lake for a specific purpose, such as for nutritional or social reasons. In fact, all ducks caught away from Lake Sempach were males, suggesting the possibility that they may have been searching for a mate at Lake Sempach where the number of Mallards was the highest [most Mallards pair up until October/November, Bezzel (1959), but often there is a surplus of males].

While home range size and the degree of movements were very variable among individuals, the activity pattern across the day was similar for all individuals. For activity (Fig. 6, Appendix Fig. 8), distance covered per half hour (Fig. 5) and flights (Fig. 6), we observed a peak around sunrise and around sunset, respectively; flying mainly occurred during nautical and civil twilight. Similar patterns have been observed in other studies on Mallard (Jorde et al. 1983) as well as for other dabbling ducks (Miller 1985; Paulus 1984). However, a comparison of night activity with data from the literature is difficult since previous behavioural studies were limited by the low visibility at night. Clearly, accelerometers provide a great advantage in terms of being able to quantify behaviour during the night.

Movements during the night were common and not influenced by moonlight in a straightforward manner. About half of the individuals showed an increase in movement activity when a narrow moon sickle was visible. During this phase of the moon, the moon is above the horizon for only a short time period per night. Therefore, a tentative explanation would be that Mallards use this short period during the night with a little moonlight to cover larger distances. When the moon is fuller, it is also above the horizon for a longer period of the night and therefore distances may be covered in more frequent but shorter flights. However, the overall picture remains inconclusive, except that Mallards displace at full moon as well as new 
moon and that they even fly during full darkness. It would appear that the light from the stars and possibly the general artificial light level in the area is enough for Mallards to move around and to land on water or on land. Similarly, some individuals foraged on fields in the absence of any sunlight or moonlight despite the abundant presence of foxes Vulpes vulpes.

Most GPS-tagged individuals moved less with increasing precipitation and with increasing wind speed, but the response to colder temperatures varied among individuals. Paulus (1988) states that movement activity generally increases with decreasing temperatures, but below $0^{\circ} \mathrm{C}$ mean day temperature, ducks often become less active and seek shelter (see also Jorde et al. 1983). Due to this nonlinearity, we also included the squared term for temperature in the model, but this did not improve the model. Therefore, we have no indication that the Mallard population changed their behaviour when the temperature fell below $0^{\circ} \mathrm{C}$ as described by Paulus (1988). Rather, we observed individual variability. It is possible that as parts of the lake shoreline froze (personal observation) and foraging opportunities at the lake were reduced, some individuals may have sought alternative feeding sites to escape competition; others remained at the lake and moved less than the ones that now ventured around the hinterland. Such disparate behaviours may have produced the variability among individuals in response to temperature. Similarly, we observed that some of the VHF-tagged individuals changed from the lake to small streams away from the lake during the coldest period of the study.

In summary, our results show a strong association of mallards with water, both day and night. Despite a common daily activity pattern centred around sunset and sunrise, movements within and between days varied considerably between individuals and, in some individuals, between periods. The degree in which Mallards used foraging sites other than the central lake varied dramatically and was not correlated in a simple way with weather or with cold spells. It is likely that the strategies adopted to deal with different situations, such as a cold spell or pair status, differed among individuals.

The intensive and largely unpredictable use of the hinterland potentially brings the Mallard in contact with domestic waterfowl or chicken, a behavioural aspect that directly bears on the spread of Avian Influenza. At Lake
Sempach, Mallards were more often than expected close to settlements, likely a consequently of people feeding the Mallards at this lake. However, on cultivated land, there was no affinity to human settlements. A transmission of Avian Influenza viruses from wild Mallards to domestic birds appears to be rather unlikely in our case because the Mallards in our study avoided the immediate vicinity of farm premises. Similarly, during $65 \mathrm{~h}$ of direct observations of outdoor enclosures on 20 farms with domestic fowl near Lake Constance (all of the enclosures were on the farm itself), no wild Mallard was observed to visit the enclosure (data A. Römer and W. Fiedler, in preparation). Despite the likely good foraging opportunities on farms (e.g. food given to domestic animals), other factors must be effective in keeping wild Mallards away day and night. An obvious potential factor is the presence of dogs, cats and humans. Urban areas and lake shore sites with public access, on the other hand, are often frequented by Mallards (Mason et al. 2006), and it has been observed that the same individual may allow humans to come close at one site but not at another (Bezzel 1959). Mallards apparently remain vigilant of humans outside of built-up areas even where hunting pressure, as in our case, is rather weak (300-400 Mallards are shot annually in the entire canton of Lucerne, of which our study perimeter accounts for $13 \%$; M. Muggli, personal communication). The highest probability of contact between Mallards and domestic waterfowl or chicken, therefore, appears to be when domestic birds are kept in open enclosures situated near a water body and away from houses.

Acknowledgments We thank Stefan Felder, Emmanuel Rey and Daniel Wili for field assistance. Josef Hofer's long-term experience catching ducks was key to the success of the study; he also caught the ducks at "obe". Martin Grüebler, Jérôme Guelat, Gabriele Hilke Peter, Verena Keller, Fränzi Korner-Nievergelt, Doris Matthes, Vreni Mattmann, Beat Naef-Danzer, Dieter Peter, David Rodrigues and Andreas Schmidt helped and advised on different aspects of the study. The study was co-funded by the Swiss Federal Veterinary Office FVO.

\section{Appendix}

Additional plots per individual for movement activity and behaviour. See Figs. 7, 8 . 

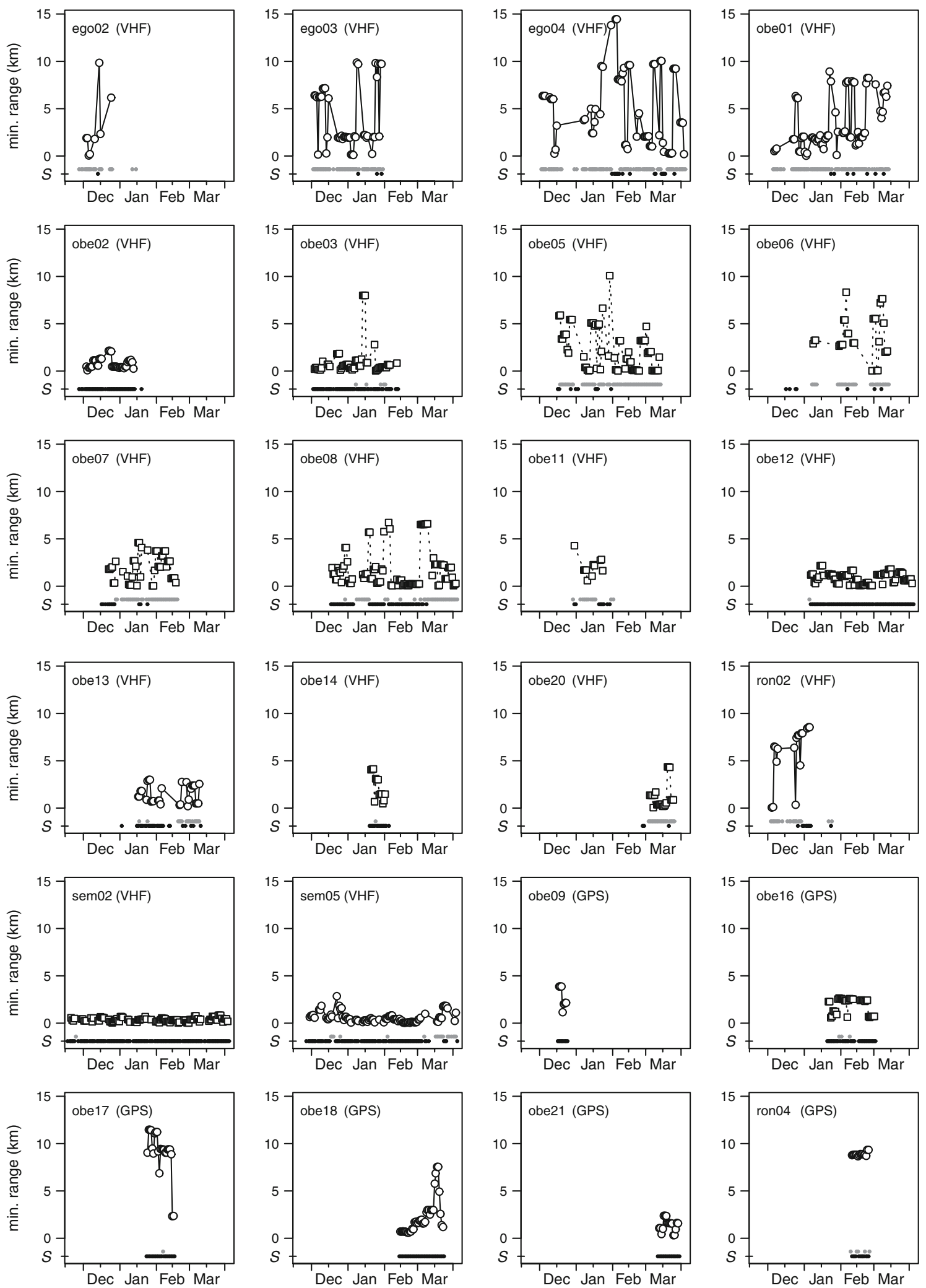

Fig. 7 As in Fig. 4, but showing all other individuals 

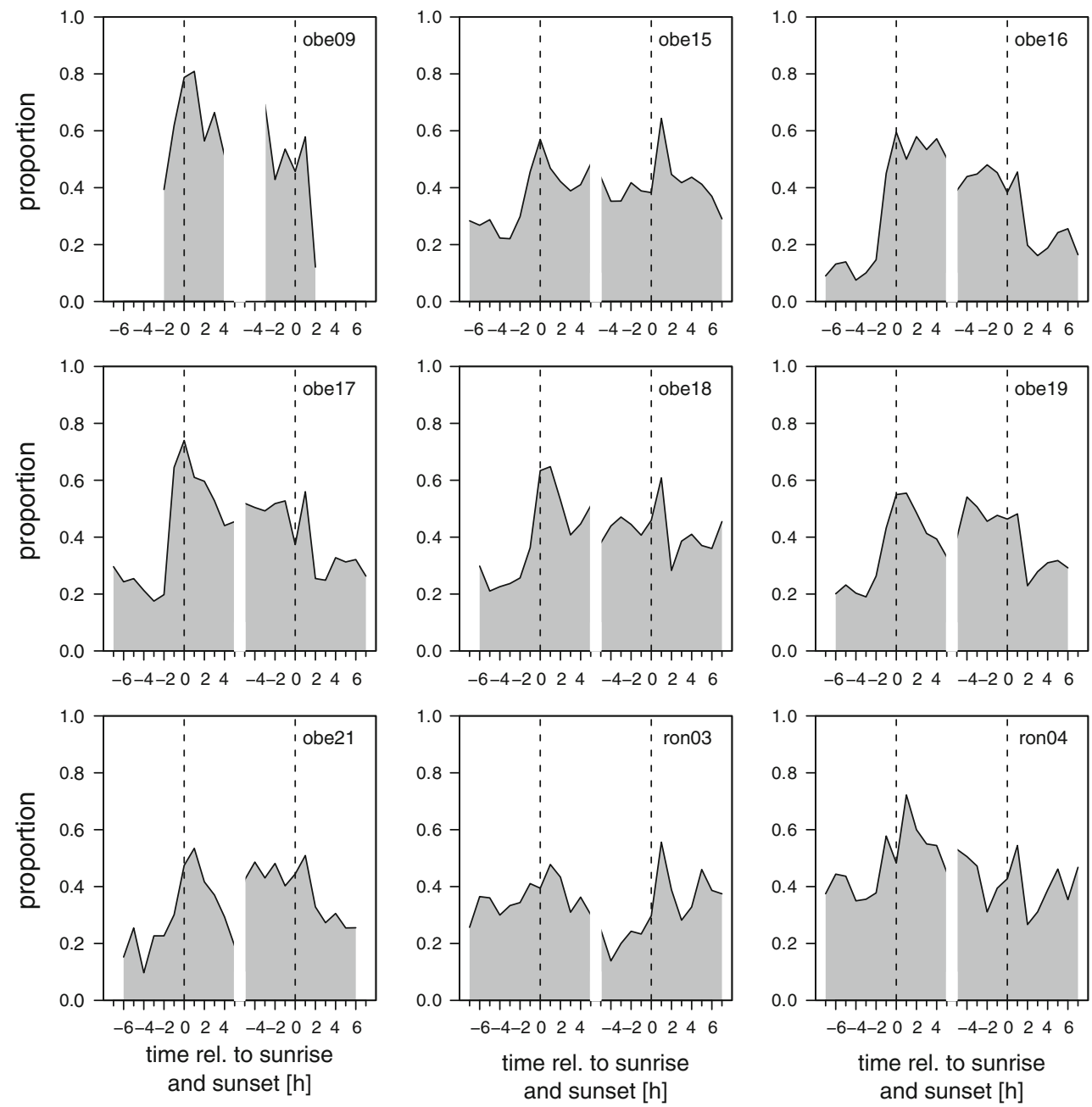

Fig. 8 As the left chart in Fig. 6, but per individual rather than averaged over the individuals. Grey shading active ducks, white inactive ducks. The top right code identifies the individual. $n>10$ localisations per hour and individual

\section{References}

Baldassarre GA, Bolen EG (1984) Field-feeding ecology of waterfowl wintering on the southern high plains of Texas. J Wildl Manage 48:63-71

Bates D, Mächler M (2010) lme4: Linear mixed-effects models using S4 classes. Available at: http://lme4.r-forge.r-project.org

Bezzel E (1959) Beiträge zur Biologie der Geschlechter bei Entenvögeln. Anz Ornithol Ges Bayern 5:269-355

Bolnick DI, Svanbäck N, Fordyce JA, Yang LH, Davis JM, Hulsey CD, Forister ML (2003) The ecology of individuals: incidence and implications of individual specialization. Am Nat 161:1-28

Bossenmair EF, Marshall WH (1958) Field-feeding by waterfowl in southwestern Manitoba. Wildl Monogr 1:1-32

Brunhart I, Falk M, Greber N, Baumer A, Globig A, Fink M, Fiedler W, Sauter A, Fiebig L, Saurina J, Zinsstag J, Conraths FJ, Stärk K, Girot C (2010) Schlussbericht Forschungsprogramm "Constanze". Bundesamt für Veterinärwesen BVET, Bern

Diefenbach DR, Nichols JD, Hines JE (1988) Distribution patterns of American Black Duck and Mallard winter band recoveries. J Wildl Manage 52:704-710
EFSA (European Food Safety Authority) (2006) Migratory birds and their possible role in the spread of highly pathogenic avian influenza. Annex EFSA J 357:1-46

Faraway JJ (2006) Extending the linear model with R. Chapman and Hall, London

Gauthier-Clerc M, Lebarbenchon C, Thomas F (2007) Recent expansion of highly pathogenic avian influenza H5N1: a critical review. Ibis 149:202-214

Gelman A, Hill J (2007) Data analysis using regression and multilevel/ hierarchical models. Cambridge University Press, Cambridge

Guillemain M, Fritz H, Duncan P (2002) The importance of protected areas as nocturnal feeding grounds for dabbling ducks wintering in western France. Biol Conserv 103:183-198

Hofer J, Korner-Nievergelt P, Korner-Nievergelt F (2010) Auftreten und Herkunft der Wasservögel am Sempachersee. Ornithol Beob Beiheft 11

Jorde DG, Krapu GL, Crawford RD (1983) Feeding ecology of Mallards wintering in Nebraska. J Wildl Manage 47:1044-1053

Jorde DG, Krapu GL, Crawford RD, Hay MA (1984) Effects of weather on habitat selection and behavior of Mallards wintering in Nebraska. Condor 86:258-265 
Keawcharoen J, van Riel D, van Amerongen G, Bestebroer T, Beyer WE, van Lavieren R, Osterhaus A, Fouchier R, Kuiken T (2008) Wild ducks as long-distance vectors of highly pathogenic avian influenza virus (H5N1). Emerg Infect Dis 14:600-607

Kozulin A (1995) Ecology of Mallards Anas platyrhynchos wintering in low temperatures conditions in Belarus. Acta Ornithol 30:125-134

Legagneux P, Blaize C, Latraube F, Gautier J, Bretagnolle V (2009) Variation in home-range size and movements of wintering dabbling ducks. J Ornithol 150:183-193

Mason CF, Hofmann TA, Macdonald SM (2006) The winter bird community of river corridors in eastern England in relation to habitat variables. Ornis Fenn 83:73-85

McNeil R, Drapeau P, Gross-Custard JD (1992) The occurrence and adaptive significance of nocturnal habits in waterfowl. Biol Rev 67:381-419

Miller MR (1985) Time budgets of Northern Pintails wintering in the Sacramento Valley, California. Wildfowl 36:65-71

Owen M (1991) Nocturnal feeding in waterfowl. Acta XX Congressus Internationalis Ornithologici, pp 1105-1112

Paulus SL (1984) Activity budgets of nonbreeding Gadwalls in Louisiana. J Wildl Manage 48:371-380

Paulus SL (1988) Time-activity budgets of nonbreeding Anatidae: a review. In: Wennerberg L (ed) Waterfowl in winter. University of Minnesota, Minneapolis, pp 135-152

Quinlan EE, Baldassarre GA (1984) Activity budgets of nonbreeding Green-winged Teal on Playa Lakes in Texas. J Wildl Manage 48:838-845
R Development Core Team (2009) R: a language and environment for statistical computing. R Foundation for Statistical Computing, Vienna. Available at: http://www.r-project.org

Robb JR (2002) Band recovery and recapture rates of American Black Ducks and Mallards. J Wildl Manage 66:153-161

Roshier DA, Klomp NI, Asmus M (2006) Movements of a nomadic waterfowl, Grey Teal, Anas garcilis, across inland Australiaresults from satellite telemetry spanning fifteen months. Ardea 94:460-475

Sauter A, Korner-Nievergelt F, Jenni L (2010) Evidence of climate change effects on within-winter movements of European Mallards Anas platyrhynchos. Ibis 152:600-609

Shepard EL, Wilson RP, Quintana F, Gomez Laich A, Liebsch N, Albareda DA, Halsey LG, Gleiss A, Morgan DT, Myers AE, Newman C, Macdonald DW (2008) Identification of animal movement patterns using tri-axial accelerometry. Endangered Spec Res 10:47-60

Tamisier A (1976) Diurnal activities of Green-winged Teal and Pintail wintering in Louisiana. Wildfowl 27:19-32

Tamisier A (1978) The functional units of wintering ducks: a spatial integration of their comfort and feeding requirements. Verh Ornithol Ges Bayern 23:229-238

Thomas GJ (1982) Autumn and winter feeding ecology of waterfowl at the Ouse Washes England. J Zool 197:131-172

Winner RW (1959) Field-feeding periodicity of Black and Mallard Ducks. J Wildl Manage 23:197-202 